\title{
Microscopic Findings Sequence Number
}

National Cancer Institute

\section{Source}

National Cancer Institute. Microscopic Findings Sequence Number. NCI Thesaurus. Code C117573.

An identifier that describes the relative position of microscopic findings data within a series. 